\title{
Avaliação da técnica de solidificação/estabilização no tratamento de resíduo têxtil - produção de bloco cerâmico de vedação
}

\section{(Evaluation of solidification/stabilization process in the treatment of textile wastes - production of ceramic blocks)}

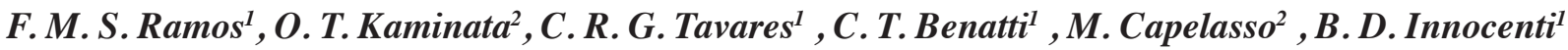 \\ ${ }^{l}$ Departamento de Engenharia Química, ${ }^{2}$ Departamento de Engenharia Civil \\ Universidade Estadual de Maringá - UEM. Maringá, PR \\ r.fabricia@gmail.com
}

\begin{abstract}
Resumo
A incorporação do resíduo têxtil em matrizes de argila para a produção de blocos cerâmicos de vedação foi avaliada por meio do processo de solidificação/estabilização (s/e). Inicialmente foi feita a caracterização do resíduo têxtil e da argila, utilizada como matriz para produção de blocos cerâmicos de vedação. A composição química deste resíduo têxtil é variada, contendo Al, Fe, Mn, $\mathrm{Na}, \mathrm{Pb}, \mathrm{Cu}, \mathrm{Cr}$ e $\mathrm{Zn}$, oriundos do processo têxtil e do tratamento do efluente gerado no processo. Sua classificação se enquadra como um resíduo não perigoso e não inerte. Posteriormente, foram preparados blocos com composição $0,5,10,15,20$ e $25 \%$ de resíduo têxtil. A mistura foi feita proporcionalmente em porcentagem de massa seca. Para análise comparativa das características químicas desses blocos cerâmicos, foram produzidos blocos somente com argila. As concentrações dos metais analisados, nos extratos lixiviados e solubilizados dos blocos cerâmicos, em todas as proporções de incorporação do resíduo têxtil, ficaram abaixo dos limites definidos pela NBR 10004/2004 da ABNT, classificando-os como não perigosos e inertes, ou seja, não oferecendo riscos de futura contaminação do solo durante a sua vida útil, bem como quando o mesmo for disposto em aterros depois de utilizados. Resultados relacionados à resistência mecânica dos blocos cerâmicos mostraram que todas as proporções de incorporação atenderam ao requisito mínimo exigido por norma. Além disso, foi possível observar que, com até $20 \%$ de resíduo têxtil incorporado à massa cerâmica, os requisitos exigidos por norma ABNT relacionados ao índice de absorção de água foram obedecidos. Assim, o processo de s/e foi capaz de imobilizar de forma eficaz os metais presentes no resíduo têxtil nos blocos cerâmicos.

Palavras-chave: argila, blocos cerâmicos, resíduo têxtil, solubilização/estabilização.
\end{abstract}

\begin{abstract}
This paper evaluates the incorporation of textile waste in claymatrices for the production of ceramic blocks with no structural function through the solidification/stabilization ( $s / s)$ process. Initially, the characterization of the textile waste and clay, used as matrices for the production of the ceramic blocks, was carried out. The chemical composition of textile waste varies and contains Al, Fe, Mn, $\mathrm{Na}, \mathrm{Pb}, \mathrm{Cu}, \mathrm{Zn}$ and $\mathrm{Cr}$, from the textile process and the treatment of sewage generated in the process. The waste was classified as a not-dangerous and not-inert residue. Afterwards, blocks with compositions 0, 5, 10, 15, 20 and 25\% of textile waste were prepared. The mixture was made proportional with a percentage of dry mass. For comparative analysis of the chemical characteristics of these blocks incorporated with textile waste, were produced ceramic blocks only with clay. The experimental results indicated that concentrations of analyzed metals in both leached and solubilized extracts from ceramic blocks with incorporation of textile waste were below the limits set by a ABNT standard for solid residue. They can then be classified as non-hazardous and inert, offering no risk of future contamination of soil during their lifetime, as well as when disposed in landfill after their use. Experimental results related to the brick compressive strength showed that all the proportions of incorporation met the requirements an ABNT standard. Results also showed that, with up to $20 \%$ of textile waste added to the bricks, water absorption met the requirements of the ABNT standard. Thus, the s/s process was able to effectively immobilize the metals present in the textile waste into the ceramic blocks. Keywords: clay, ceramic blocks, textile waste, solidification/stabilization.
\end{abstract}

\section{INTRODUÇÃO}

Com o desenvolvimento tecnológico, o número de indústrias no mundo vem crescendo a cada dia e com elas a quantidade de lodos e resíduos industriais. Este problema é comum em várias partes do Brasil e do mundo. Hoje, com as novas leis de proteção ao ambiente, e a crescente e progressiva implantação de novas e exigentes diretrizes na gestão de lodos e resíduos para as sociedades industrializadas, na perspectiva de um desenvolvimento sustentável, faz-se necessário desenvolver métodos alternativos e eficazes, em substituição ao simples descarte desses em aterros sanitários. Em vista disto, muitos estudos vêm sendo desenvolvidos no sentido de valorizar lodos e resíduos de diferentes naturezas, 
utilizando-os como matéria prima para produção de um material utilizável [1].

$\mathrm{O}$ aproveitamento dos rejeitos industriais, como materiais alternativos não é novo, e tem dado certo em vários países do Primeiro Mundo. Algumas das principais razões que motivam os países a reciclarem seus rejeitos industriais são o esgotamento das reservas de matérias-primas confiáveis bem como o crescente volume de resíduos sólidos, que põem em risco a saúde pública, ocupam espaço e degradam os recursos naturais [2]. Nesse sentido, a incorporação de resíduos industriais em matriz cerâmica para utilização na construção civil vem sendo amplamente estudada. A construção civil é um ramo da atividade tecnológica que, pelo volume de recursos naturais consumidos, pode ser largamente indicado para absorver resíduos sólidos [3].

A técnica de s/e é umas das formas de tratamento e disposição dos resíduos industriais. O processo de s/e utiliza formulações quimicamente reativas que, em conjunto com a água e outros componentes do lodo, formam sólidos estáveis [4]. O material utilizado para s/e, além de solidificar o resíduo perigoso por meios químicos, insolubiliza, imobiliza, encapsula, destrói ou interage com os componentes do resíduo utilizado. Os resultados dessas interações são sólidos não-perigosos ou menos perigosos que o resíduo original. A técnica de utilização de lodo, como um aditivo em materiais de construção civil, incluindo blocos cerâmicos, não somente converte os resíduos em materiais utilizáveis, mas também alivia os problemas de disposição [5]. Os benefícios do uso de resíduos como aditivos cerâmicos incluem a imobilização de metais pesados na matriz queimada, oxidação da matéria orgânica e destruição de qualquer organismo patogênico durante o processo de queima. O objetivo deste trabalho foi avaliar o processo de lixiviação e solubilização de metais, de blocos cerâmicos fabricados a partir da técnica de s/e, de lodo proveniente da indústria têxtil, em matriz de argila, em diferentes proporções.

\section{MATERIAIS E MÉTODOS}

O resíduo (lodo) utilizado foi proveniente de 14 indústrias têxteis da região de Maringá, PR. Estes resíduos foram coletados em estado semi-seco e, misturados e homogeneizados em quantidades iguais determinadas em porcentagem de massa seca. O lodo foi caracterizado quanto ao teor de umidade e matéria orgânica total [6], massa específica (método do picnômetro), pH [7], análise química (relacionada aos metais relacionados na NBR 10004/2004 [14] por meio da extração à digestão ácida, com ácido fluorídrico e água régia) e quanto suas características tóxicas relacionada aos procedimentos de lixiviação [8] e solubilização [9].

Para determinação dos elementos químicos dos extratos lixiviados e solubilizados, bem como o extrato da digestão ácida foi utilizado o espectrofotômetro de absorção atômica Varian SpectrAA 50B.

A matriz sólida utilizada foi argila proveniente de uma olaria situada na cidade de Japurá, PR. Foi caracterizada quanto ao teor de umidade e matéria orgânica total [6], $\mathrm{pH}$ [7], análise granulométrica [10], limite de plasticidade [11], limite de liquidez [12], massa específica, análise química (relacionada aos metais por meio da extração à digestão ácida, com ácido fluorídrico e água régia e leitura em espectrofotômetro de absorção atômica).

A argila e o resíduo foram triturados em moinho de barras cilíndrico com capacidade $0,1 \mathrm{~m}^{3}$, com movimento de 30 rpm, passando em seguida pela peneira $10 \mathrm{com}$ malha de 2,5 $\mathrm{mm}$, para posterior mistura, em porcentagem de massa seca, e homogeneização. O peneiramento foi necessário para que partículas sólidas não obstruíssem a boquilha da extrusora, comprometendo a qualidade dos blocos.

Foram confeccionados, em extrusora de laboratório, blocos cerâmicos nas proporções de $0,5,10,15,20$ e $25 \%$ de resíduo têxtil. Para análise comparativa das características químicas, físicas e mecânicas desses blocos cerâmicos, foram produzidos blocos somente com argila. Após a mistura e homogeneização, a massa foi transferida para recipiente de amassamento, adicionando-se água de forma gradativa, até formar uma massa consistente com plasticidade a ponto de abastecer a extrusora Gerenski MVIG-05. Dessa forma, foram produzidos blocos de vedação em escala reduzida de $1: 3$, ou seja, paredes e septos de 2,5 mm, largura de $33 \mathrm{~mm}$, altura de $50 \mathrm{~mm}$ e comprimento de $67 \mathrm{~mm}$.

Os blocos cerâmicos foram secos em temperatura ambiente em local fechado e ventilado durante 7 dias para evaporação da água absorvida. Em seguida, queimados em forno de olaria a $850{ }^{\circ} \mathrm{C}$ durante $72 \mathrm{~h}$. Nesse processo, observou-se cuidados com a manutenção da temperatura do forno, mantendo-se constante durante $48 \mathrm{~h}$, sendo gradativo o aquecimento inicial nas primeiras $12 \mathrm{~h}$, e gradativo também o desaquecimento durante as últimas $12 \mathrm{~h}$. Posteriormente, os blocos foram resfriados com ventilação forçada (durante 12 h), até alcançar a temperatura ambiente para o recolhimento do material pronto para análise.

A caracterização dos blocos cerâmicos foi feita em microscópio eletrônico de varredura Shimadzu SS-550, quanto às suas características tóxicas, relacionadas aos procedimentos de lixiviação [8] e solubilização [9], e quanto às suas características físicas e mecânicas, relacionadas aos procedimentos de determinação do índice de absorção de água [18] e resistência à compressão [18], respectivamente.

\section{RESULTADOS E DISCUSSÃO}

\section{Caracterização do lodo e da argila}

A Tabela I apresenta os resultados da caracterização do lodo e da argila, bem como os resultados das análises de metais.

Esses resultados mostram que o lodo proveniente da indústria têxtil contém uma grande quantidade de alumínio, ferro, manganês e sódio. Provavelmente estes metais são resultado do processo de tratamento dos efluentes têxteis, que na maioria das indústrias objeto do presente trabalho, é feito por processo de coagualção/floculação, utilizando sulfato de 
Tabela I - Características do resíduo têxtil (lodo) e da argila. [Table I - Characteristics of textile waste and clay.]

\begin{tabular}{lll}
\hline Parâmetros & Lodo & Argila \\
\hline Aspecto & pastoso & seco \\
$\mathrm{pH}$ & 7,8 & 5,3 \\
Densidade $\left(\mathrm{g} / \mathrm{cm}^{3}\right)$ & 1,95 & 2,8 \\
Matéria Orgânica Total ( \% ) & 41,0 & 5,0 \\
Umidade (\%) & 21,5 & 6,5 \\
Metais ( mg/Kg ) & & \\
$\mathrm{Al}$ & $62.966,7$ & $67.823,9$ \\
$\mathrm{~Pb}$ & 174,7 & 47,9 \\
$\mathrm{Cu}$ & 287,5 & 40,3 \\
$\mathrm{Cr}$ & 195,0 & 69,5 \\
$\mathrm{Fe}$ & $35.172,4$ & $32.136,4$ \\
$\mathrm{Mn}$ & $1.106,1$ & 890,9 \\
$\mathrm{Na}$ & $33.275,3$ & $7.045,8$ \\
$\mathrm{Zn}$ & 294,4 & 151,2 \\
$\mathrm{Ag}$ & $\mathrm{n} . \mathrm{d}$ & $\mathrm{n} . \mathrm{d}$ \\
$\mathrm{Ba}$ & $\mathrm{n} . \mathrm{d}$ & $\mathrm{n} . \mathrm{d}$ \\
$\mathrm{Cd}$ & n.d & n.d \\
$\mathrm{As}$ & n.d & n.d \\
$\mathrm{Ba}$ & n.d & n.d \\
$\mathrm{Hg}$ & n.d & n.d \\
$\mathrm{Se}$ & n.d & n.d \\
\hline n.d: valor não detectado pelo aparelho. & & \\
& &
\end{tabular}

alumínio e cloreto férrico como agentes coagulantes. Devido às impurezas inerentes à matéria-prima têxtil, ou seja, aquelas oriundas dos processos de fiação e tecelagem, bem como de produtos auxiliares ou corantes, que possam ser eliminados durante as diferentes etapas de acabamento, há a ocorrência de contaminantes [13], os quais podem estar relacionados com a presença de $\mathrm{Pb}, \mathrm{Cu}, \mathrm{Cr}$ e $\mathrm{Zn}$ encontrados na analise química do resíduo bruto. Dentre os metais analisados, arsênio, bário, mercúrio e selênio não foram detectados no resíduo em questão. Os metais contidos na argila podem ter origem nos processos naturais, como a decomposição de rochas ou minerais. A quantidade destes metais pode ser determinada pelo teor dos mesmos, presentes nas rochas, e pelo grau de intemperização que essas rochas possam sofrer. O conteúdo de matéria orgânica, assim como a umidade, também são parâmetros importantes, pois estes podem influenciar na qualidade final dos blocos cerâmicos. Conforme resultados apresentados na Tabela I, verifica-se que o resíduo têxtil em questão contém $41 \%$ de matéria orgânica e a argila utilizada no processo contém $5 \%$. A importância da quantificação do conteúdo de matéria orgânica deve-se ao processo de queima dos blocos cerâmicos, ocasionando a volatilização da mesma, causando, desta forma, perda de massa, formação de poros ou blocos com baixa densidade, influenciando na resistência e qualidade dos blocos cerâmicos.

As Tabelas II e III apresentam os resultados das análises
Tabela II - Características tóxicas do resíduo (procedimentos de lixiviação - NBR 10005/2004).

[Table II - Toxic characteristics of textile waste (leaching procedure - NBR 10005/2004.]

\begin{tabular}{ccc}
\hline Metais & $\begin{array}{c}\text { Concentração } \\
(\mathrm{mg} / \mathrm{L})\end{array}$ & $\begin{array}{c}\text { Lim. Máx. (mg/L) } \\
\text { NBR 10004/2004 } \\
\text { (Anexo F) }\end{array}$ \\
\hline Arsênio & $\mathrm{n} . \mathrm{d}$ & 1,0 \\
Bário & $\mathrm{n} . \mathrm{d}$ & 70,0 \\
Cádmio & $\mathrm{n} . \mathrm{d}$ & 0,5 \\
Chumbo & $\mathrm{n} . \mathrm{d}$ & 1,0 \\
Cromo & $\mathrm{n} . \mathrm{d}$ & 5,0 \\
Mercúrio & $\mathrm{n} . \mathrm{d}$ & 0,1 \\
Prata & $\mathrm{n} . \mathrm{d}$ & 5,0 \\
Selênio & $\mathrm{n} . \mathrm{d}$ & 5,0 \\
\hline n.d: não detectado. & &
\end{tabular}

Tabela III - Características tóxicas do resíduo (procedimentos de solubilização - NBR 10006/2004).

[Table III - Toxic characteristics of textile waste (solubilization procedure - NBR 10006/2004.]

\begin{tabular}{ccc}
\hline Metais & $\begin{array}{c}\text { Concentração } \\
(\mathrm{mg} / \mathrm{L})\end{array}$ & $\begin{array}{c}\text { Lim. Máx. (mg/L) } \\
\text { NBR 10004/2004 } \\
\text { (Anexo G) }\end{array}$ \\
\hline Arsênio & n.d & 0,01 \\
Bário & n.d & 0,7 \\
Cádmio & n.d & 0,005 \\
Chumbo & 0,07 & 0,01 \\
Cromo & 0,05 & 0,05 \\
Mercúrio & n.d & 0,001 \\
Prata & n.d & 0,05 \\
Selênio & n.d & 0,01 \\
Alumínio & 0,3 & 0,2 \\
Cobre & n.d & 2,0 \\
Ferro & n.d & 0,3 \\
Zinco & 0,06 & 5,0 \\
Manganês & 4,2 & 0,1 \\
Sódio & 285,3 & 200,0 \\
\hline
\end{tabular}

n.d: valor não detectado pelo aparelho.

de caracterização tóxica, relacionadas aos procedimentos de lixiviação [8] e solubilização [9] do resíduo têxtil; respectivamente.

A Tabela II mostra a análise do extrato lixiviado do resíduo têxtil. Esta análise visa diferenciar os resíduos classificados pela NBR 10004/2004 [14] como classe I - perigosos - e classe II - não perigosos. Este teste permite avaliar o grau de imobilização dos contaminantes quando em contato com soluções aquosas, que podem ser encontradas em um aterro 
[15]. Os metais relacionados na NBR 10004/2004 (anexo F) da ABNT não foram detectados no extrato lixiviado, podendo ser classificado, portanto, como um resíduo de classe II ou não perigoso.

A análise dos resultados da Tabela III visa diferenciar os resíduos classificados na NBR 10004/2004 (anexo G) da ABNT como classe II A - não inertes - e classe II B - inertes. Os resultados das concentrações dos metais presentes no extrato solubilizado mostram que, $\mathrm{Al}, \mathrm{Pb}, \mathrm{Mn}$ e $\mathrm{Na}$, estão acima dos limites estabelecidos, demonstrando que no resíduo têxtil há ocorrência de metais que solubilizam em quantidades superiores aos permitidos pela NBR 10004/2004 da ABNT, o que leva a classificá-lo como um resíduo de classe IIA, ou não inerte. Ressaltando-se que estes elementos são originários do processo de tratamento de efluentes, bem como dos processos têxteis. Os resultados de caracterização do lodo mostram que este resíduo não pode ser descartado em aterros comuns, devendo sofrer um processo de tratamento ou ser disposto em aterros industriais. Para o caso da região de Maringá, isto se torna um problema uma vez que não há aterros industriais, o que encarece de forma substancial o processo de disposição destes resíduos, aliado a isto há ainda a questão da co-responsabilidade do gerador de resíduos, com respeito à sua destinação.

As Tabelas IV e V apresentam os resultados da composição granulométrica e plasticidade da argila, respectivamente.

A amostra de argila utilizada apresenta características físicas apropriadas para produção de materiais de boa qualidade, visto que, por meio da análise granulométrica, verificou-se que $50 \%$ da argila bruta refere-se à fração argila, ou seja, trata-se de um material extremamente coeso, contendo principalmente, partículas da fração argila e silte, que são preponderantes para formação da rigidez durante a queima em forno, à temperatura de $850{ }^{\circ} \mathrm{C}$. A argila estudada é considerada um material de alta plasticidade (LP > 15\%). Segundo [16] o limite de plasticidade indicado para cerâmica vermelha, varia entre 17,2 e $32 \%$ e, para o processo de extrusão, este limite tem que estar entre $26 \mathrm{e}$ $32 \%$. Assim, a argila utilizada é aplicável para a produção de blocos cerâmicos por extrusão. O limite de liquidez (LL)
Tabela IV - Análise granulométrica da argila. [Table IV - Granulometric analysis of clay.]

\begin{tabular}{ccccc}
\hline Amostra & $\begin{array}{c}\text { Argila } \\
(\%)\end{array}$ & $\begin{array}{c}\text { Silte } \\
(\%)\end{array}$ & $\begin{array}{c}\text { Areia Fina } \\
(\%)\end{array}$ & $\begin{array}{c}\text { Areia Grossa } \\
(\%)\end{array}$ \\
\hline Argila Bruta & 50 & 35 & 10 & 5 \\
\hline
\end{tabular}

Tabela V - Plasticidade da argila.

[Table V - Plastic index of clay.]

\begin{tabular}{cc}
\hline Parâmetro & Argila \\
\hline Limite de Plasticidade - LP ( \% ) & 26 \\
Limite de Liquidez - LL ( \% ) & 61 \\
Índice de Plasticidade - IP ( \% ) & 35 \\
\hline
\end{tabular}

foi superior a 50\%, o que indica que esta argila apresenta uma alta compressibilidade. De acordo com [17] no caso específico da tecnologia cerâmica, para moldagem de tijolos furados por extrusão, a faixas de limite de liquidez (LL) e índice de plasticidade (IP), recomendadas para argilas plásticas, correspondem a: LL variando de $26,50 \%$ a $71,60 \%$ e IP variando de $4,00 \%$ a $47,70 \%$.

\section{Caracterização dos blocos cerâmicos}

As Tabelas VI e VII referem-se às análises dos extratos lixiviados e solubilizados, segundo a NBR 10005/2004 e NBR 10006/2004, dos blocos cerâmicos, preparados com $0,5,10,15,20$ e $25 \%$ de resíduo têxtil. A Fig. 1 refere-se à microscopia eletrônica de varredura (MEV) realizada nos blocos cerâmicos incorporados com $0,5,10,15,20$ e $25 \%$ de resíduo têxtil.

Esses resultados mostram que as concentrações dos metais nos extratos lixiviados e solubilizados dos blocos cerâmicos, em todas as proporções de incorporação do resíduo, estão abaixo dos limites definidos pela NBR 10004/2004 da ABNT - Resíduos Sólidos, classificando-os como não perigosos e inertes, ou seja, os elementos químicos

Tabela VI - Concentração de metais do extrato lixiviado dos blocos cerâmicos (NBR 10005/2004). [Table VI - Metal concentrations in leached extracts (NBR 10005/2004).]

\begin{tabular}{cccccccc}
\hline Metais & $\begin{array}{c}0 \% \\
(\mathrm{mg} / \mathrm{L})\end{array}$ & $\begin{array}{c}5 \% \\
(\mathrm{mg} / \mathrm{L})\end{array}$ & $\begin{array}{c}10 \% \\
(\mathrm{mg} / \mathrm{L})\end{array}$ & $\begin{array}{c}15 \% \\
(\mathrm{mg} / \mathrm{L})\end{array}$ & $\begin{array}{c}20 \% \\
(\mathrm{mg} / \mathrm{L})\end{array}$ & $\begin{array}{c}25 \% \\
(\mathrm{mg} / \mathrm{L})\end{array}$ & $\begin{array}{c}\text { Lim. Máx. } \\
(\mathrm{mg} / \mathrm{L})\end{array}$ \\
\hline Arsênio & n.d & n.d & n.d & n.d & n.d & n.d & 1,0 \\
Bário & n.d & n.d & n.d & n.d & n.d & n.d & 70,0 \\
Cádmio & n.d & n.d & n.d & n.d & n.d & n.d & 0,5 \\
Chumbo & n.d & n.d & n.d & n.d & n.d & n.d & 1,0 \\
Cromo & n.d & n.d & 0,011 & 0,015 & 0,017 & 0,018 & 5,0 \\
Mercúrio & n.d & n.d & n.d & n.d & n.d & n.d & 0,1 \\
Prata & n.d & n.d & n.d & n.d & n.d & n.d & 5,0 \\
Selênio & n.d & n.d & n.d & n.d & n.d & n.d & 5,0 \\
\hline
\end{tabular}

n.d: valor não detectado pelo aparelho. 
Tabela VII - Concentração de metais do extrato solubilizado dos blocos cerâmicos (NBR 10006/2004).

[Table VII - Metal concentrations in solubilized extracts (NBR 10006/2004).]

\begin{tabular}{cccccccc}
\hline Metais & $0 \%$ & $5 \%$ & $10 \%$ & $15 \%$ & $20 \%$ & $25 \%$ & $\begin{array}{c}\text { Lim. Máx. } \\
(\mathrm{mg} / \mathrm{L})\end{array}$ \\
\hline Alumínio & n.d & n.d & n.d & n.d & n.d & n.d & 0,2 \\
Arsênio & n.d & n.d & n.d & n.d & n.d & n.d & 0,01 \\
Bário & n.d & n.d & n.d & n.d & n.d & n.d & 0,7 \\
Cádmio & n.d & n.d & n.d & n.d & n.d & n.d & 0,005 \\
Chumbo & n.d & n.d & n.d & n.d & n.d & n.d & 0,01 \\
Cobre & n.d & n.d & n.d & n.d & n.d & n.d & 2,0 \\
Cromo & n.d & 0,001 & 0,002 & 0,003 & 0,009 & 0,024 & 0,05 \\
Ferro & n.d & n.d & n.d & n.d & n.d & n.d & 0,3 \\
Manganês & n.d & n.d & n.d & n.d & n.d & n.d & 0,1 \\
Mercúrio & n.d & n.d & n.d & n.d & n.d & n.d & 0,001 \\
Prata & n.d & n.d & n.d & n.d & n.d & n.d & 0,05 \\
Sódio & 1,9 & 4,5 & 6,6 & 6,9 & 7,8 & 45,1 & 200,0 \\
Zinco & n.d & n.d & n.d & n.d & n.d & n.d & 5,0 \\
Selênio & n.d & n.d & n.d & n.d & n.d & n.d & 0,01 \\
\hline
\end{tabular}

n.d: valor não detectado.
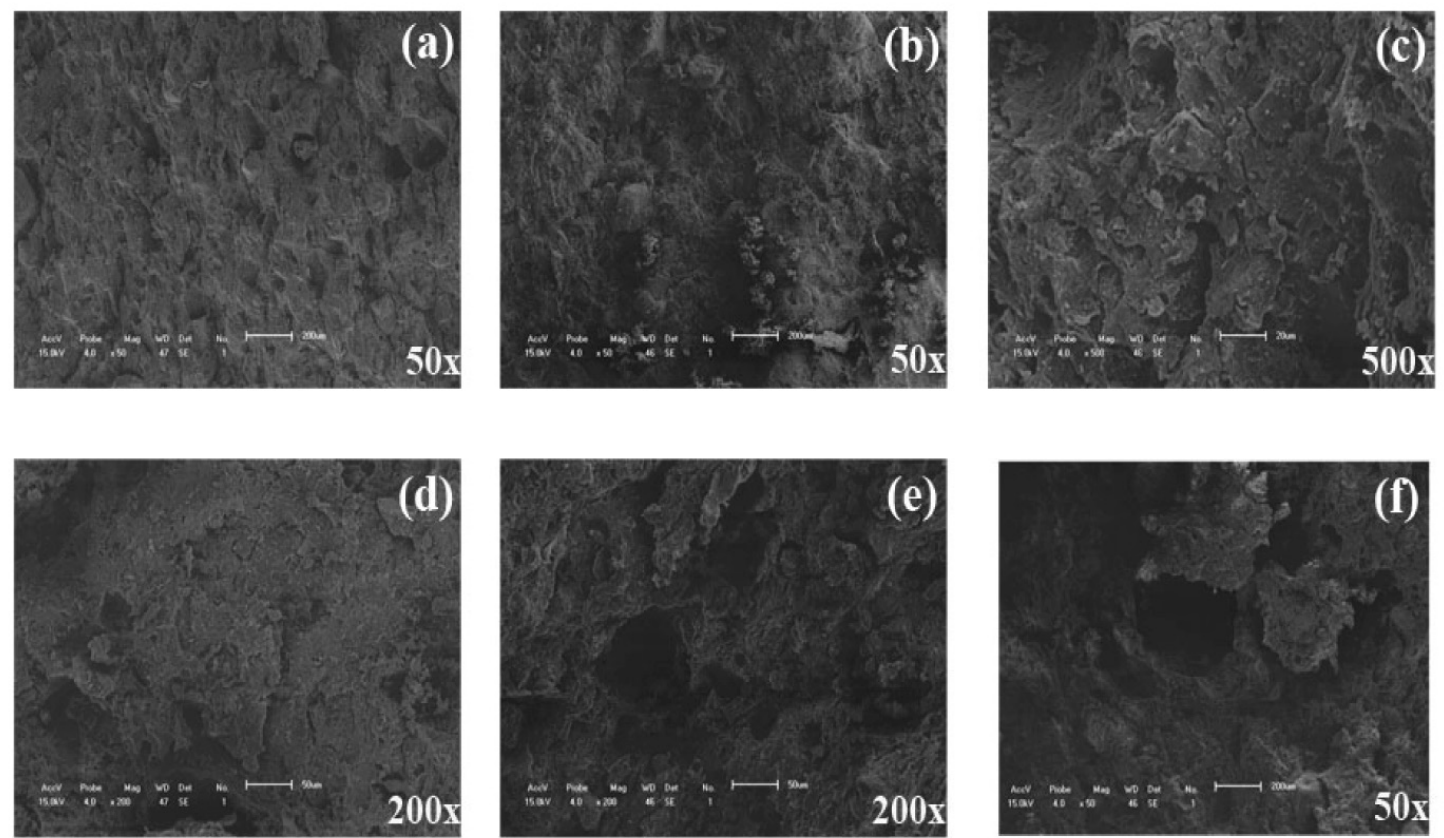

Figura 1: Microscopia eletrônica de varredura. (a) bloco cerâmico somente com argila; (b) bloco cerâmico com 5\% de resíduo têxtil incorporado; (c) bloco cerâmico com 10\% de resíduo têxtil incorporado; (d) bloco cerâmico com 15\% de resíduo têxtil incorporado; (e) bloco cerâmico com $20 \%$ de resíduo têxtil incorporado; (f) bloco cerâmico com $25 \%$ de resíduo têxtil incorporado.

[Figure 1: Scanning electron micrographs. (a) ceramic blocks only with clay; (b) ceramic blocks incorporated with 5\% of textile waste; (c) ceramic blocks incorporated with 10\% of textile waste; (d) ceramic blocks incorporated with1 5\% of textile waste; (e) ceramic blocks incorporated with $20 \%$ of textile waste; (f) ceramic blocks incorporated with $25 \%$ of textile waste.]

contidos no resíduo têxtil incorporado na massa cerâmica permanecerão imobilizados no material cerâmico, sem haver prejuízos ou riscos de futura contaminação do solo durante a sua vida útil, bem como quando o mesmo for disposto em aterros. Dessa forma, pode-se observar que o processo de Solidificação/Estabilização (S/E) foi capaz de imobilizar de forma eficaz os metais nos blocos cerâmicos.

Podem-se observar as diferenças nas estruturas formadas 
após a queima. Comparando-se a Fig. 1a com as demais figuras, é possível observar nitidamente a dimensão mais ampla dos poros formados na massa cerâmica incorporado com o resíduo têxtil, justificada pela volatilização da matéria orgânica e umidade, presentes no resíduo (lodo) e argila, durante a queima, devido provavelmente à vitrificação dos blocos cerâmicos.

As Figs. 2 e 3 referem-se aos resultados da determinação das características físicas e mecânicas dos blocos cerâmicos preparados com $0,5,10,15,20$ e $25 \%$ em massa de resíduo têxtil.

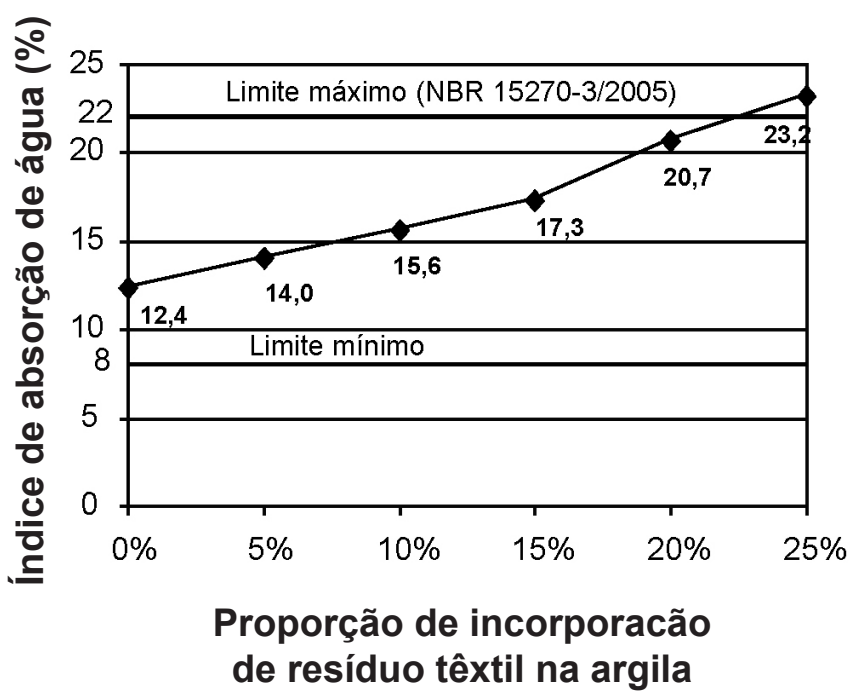

Figura 2: Índice de absorção de água em amostras dos blocos cerâmicos.

[Figure 2: Bricks water absorption.]

O objetivo do ensaio de determinação do índice de absorção de água é a verificação da porcentagem de água absorvida no período de $24 \mathrm{~h}$ em temperatura ambiente, e está diretamente relacionada com o índice de vazios da massa estrutural do bloco cerâmico, isto é, quanto maior a quantidade de água absorvida, maior a porosidade existente na massa cerâmica. De acordo com norma, o índice de absorção de água não deve ser inferior a $8 \%$ nem superior a $22 \%$.

Assim, a Fig. 2 apresenta a evolução do processo de absorção de água, obtida em blocos cerâmicos em escala 1:3. Pode-se observar que o aumento do teor de resíduo têxtil aumentou a absorção de água, chegando-se a um limite de $20 \%$ de resíduo, sem que se ultrapassasse o limite estabelecido na norma da ABNT. No entanto, o valor da absorção de água para esse teor de resíduo na massa cerâmica ficou muito próximo do limite máximo estabelecido.

Paredes construídas com esses blocos cerâmicos podem sofrer aumento de carga quando expostas à chuva, podendo acarretar problemas estruturais à construção [19]. Esse problema fica mais evidente quando se observa casas populares que, devido à condição econômica precária de seus moradores, permanecem "cruas", ou seja, sem qualquer

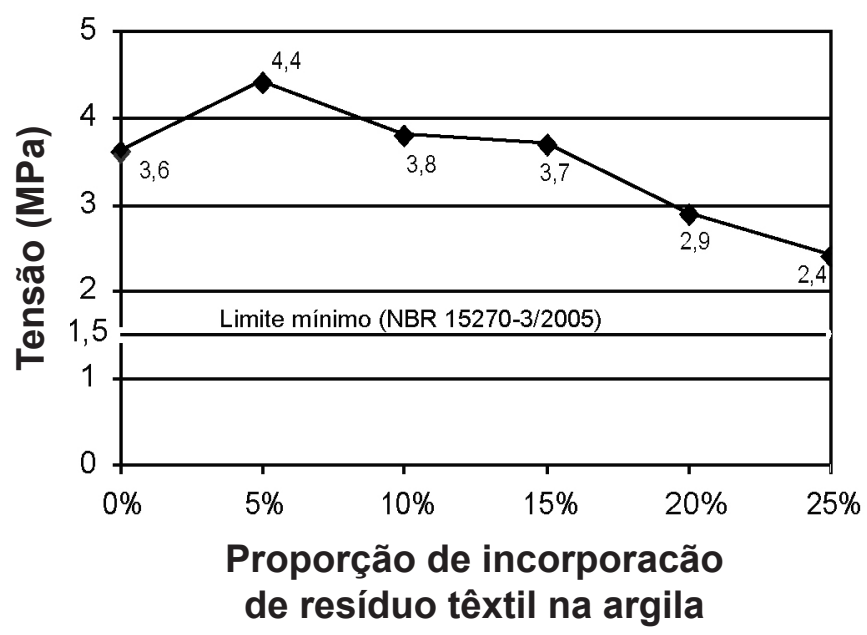

Figura 3: Resistência à compressão em amostras dos blocos cerâmicos.

[Figure 3: Bricks compressive strength.]

revestimento que proteja suas paredes. Além disso, paredes de blocos cerâmicos de vedação com alta absorção de água apresentam problemas na aderência da argamassa de reboco, pois a água existente na composição da argamassa é absorvida, resultando em uma massa seca sem poder de fixação.

O ensaio de resistência à compressão tem o objetivo de verificar a capacidade de carga que os blocos cerâmicos podem suportar quando submetidos a uma força exercida perpendicularmente sobre suas faces opostas, determinando, desta forma, se as amostras oferecem resistências mecânicas adequadas, simulando a pressão exercida pelo peso da construção sobre os blocos. As amostras de blocos cerâmicos de vedação devem atender ao requisito mínimo de 1,5 $\mathrm{MPa}$ de acordo com a norma. $\mathrm{O}$ não atendimento aos parâmetros normativos mínimos indica que a parede poderá apresentar problemas estruturais como rachaduras e, conseqüentemente, oferecerá riscos de desabamento da construção.

Assim, a Fig. 3 apresenta a evolução da resistência mecânica dos blocos cerâmicos, em função do teor de resíduo sólido incorporado à mesma. A adição de $5 \%$ de resíduo à massa cerâmica, levou um aumento de resistência, superando em $22 \%$ a resistência do bloco controle. Nas proporções de $5 \%, 10 \%$ e $15 \%$ os valores de resistência foram superiores aos blocos de controle produzidos apenas com argila. Amostras com 25\% de resíduo, foram menos resistentes, cerca de $33 \%$ menor que a resistência do bloco de controle. Verificou-se, no entanto, que a resistência mecânica dos blocos cerâmicos produzidos, para todos os teores de incorporação de resíduo têxtil, atendeu aos limites mínimos especificados por norma.

\section{CONCLUSÕES}

O processo de s/e para incorporação de resíduo têxtil à massa cerâmica mostrou-se bastante eficiente no sentido de reaproveitamento do mesmo em bloco cerâmico. Esse processo beneficiará o gerador do resíduo têxtil, uma 
vez que o mesmo poderá se tornar uma alternativa eficaz de tratamento do resíduo. Este processo traz vantagens consideráveis para a indústria de cerâmica vermelha, considerando que haverá minimização do uso da argila como matéria-prima, sem comprometer a qualidade do produto final. Este processo também reduz os impactos negativos causados pelo extrativismo da argila, bem como riscos à saúde pública, com relação à disposição inadequada do resíduo têxtil.

Nos ensaios relacionados às características tóxicas referentes aos procedimentos de lixiviação e solubilização, com $0,5,10,15,20$ e $25 \%$ de resíduo têxtil incorporado na massa de argila, os resultados mostraram que todas as proporções são possíveis de serem utilizadas, uma vez que as concentrações de metais nos extratos lixiviados e solubilizados dos blocos cerâmicos, estavam abaixo dos limites definidos pela NBR 10004/2004 da ABNT - Resíduos Sólidos. Os metais encontrados no resíduo permaneceram encapsulados no material cerâmico, após a queima em alta temperatura do forno de olaria, possibilitando o uso desses blocos na construção civil, sem que haja riscos de contaminação durante o período de utilização, bem como em sua disposição final nos aterros, após o período de vida útil.

Nos ensaios relacionados às características físicas e mecânicas, referentes aos procedimentos de determinação do índice de absorção de água e resistência à compressão (NBR 15270-3/2005), todos as proporções de incorporação de resíduo têxtil à massa cerâmica respeitaram o limite mínimo exigido por norma para o ensaio de determinação de resistência à compressão, porém, para o ensaio de determinação do índice de absorção de água foi atingido um limite de $20 \%$ de incorporação de resíduo têxtil à massa, sem que o mesmo excedesse os limites estabelecidos pela referida norma.

Portanto, foi possível comprovar a eficácia do processo de s/e no que se refere à asseguração quanto aos riscos ao ambiente bem como aos requisitos de qualidade do bloco cerâmico.

\section{AGRADECIMENTOS}

Aos Departamentos de Engenharia Química e de Engenharia Civil da Universidade Estadual de Maringá, ao CNPq e à FINEP/SEBRAE, pelo apoio financeiro.

\section{REFERÊNCIAS}

[1] A. H. Moreira, R. M. Oliveira, P. D. S. Lima, Cerâmica 47, 303 (2001) 158-162.

[2] R. R. Menezes, G. A. Neves, H. C. Ferreira, Rev. Bras. Eng. Agríc. Ambient 6, 2 (2002) 303-313.
[3] P. O. Giffoni, L. C. Lange, Eng. Sanitária Ambiental 10, 2 (2005) 128-136.

[4] R. Malviya, R. Chaudhary, J. Hazardous Mater. 137, 1 (2006) 267-276.

[5] C.-H. Weng, D.-F. Lin, P.-C Chiang, Advances Environmental Res. 7 (2003) 679-685.

[6] E. J. Kiehl, Fertilizantes orgânicos, Editora Agronômica CERES Ltda., S. Paulo (1985) 492p.

[7] APHA, Standard Methods for the Examination of Water \& Wastewater, Método 4500- $\mathrm{H}^{+} \mathrm{B}, 21$ Ed., Washington, EUA (2005).

[8] Associação Brasileira de Normas Técnicas-ABNT, Procedimento para obtenção de extrato lixiviado de resíduos sólidos, NBR 10.005/2004, Rio de Janeiro, RJ (2004).

[9] Associação Brasileira de Normas Técnicas-ABNT, Procedimento para obtenção de extrato solubilizado de resíduos sólidos, NBR 10.006/2004, Rio de Janeiro, RJ (2004).

[10] Associação Brasileira de Normas Técnicas-ABNT, Solo - Análise granulométrica, NBR 7181/1984, Rio de Janeiro, RJ (1984).

[11] Associação Brasileira de Normas Técnicas-ABNT, Solo - Determinação do limite de plasticidade, NBR 7480/1984, Rio de Janeiro, RJ (1984).

[12] Associação Brasileira de Normas Técnicas-ABNT, Solo - Determinação do limite de liquidez, NBR 6459/1984, Rio de Janeiro, RJ (1984).

[13] E. V. C. Rosa, Reaproveitamento de lodo têxtil em solo florestal: Estudos dos aspectos físico-químicos, agronômicos e ecotoxicológicos, Tese, Universidade Federal de Santa Catarina, UFSC (2004).

[14] Associação Brasileira de Normas Técnicas-ABNT, Resíduos Sólidos, NBR 10.004/2004. Rio de Janeiro, RJ (2004).

[15] A. A. C. Rocca, A. A. C. Iacovone, A. J. Barrotti, D. C. Casarini, E. Gloeden, E. L. Straus, J. A. Romano, L. R. Ruiz, L. M. Silva, L. M. Saito, M. C. Pires, M. L. G. Leão, P. P. C. Neto, R. Colluci, R. C. A. Cunha, Resíduos Sólidos Industriais, CETESB, S. Paulo, SP (1993).

[16] S. R. Teixeira, S. A. Souza, C. A. I. Moura, Cerâmica 47, 304 (2001) 204-207.

[17] L. F. A. Campos, R. S. Macedo, P. K. Kiyohara, H. C. Ferreira, Cerâmica 45, 295 (1999) 140-145.

[18] Associação Brasileira de Normas Técnicas-ABNT, Blocos cerâmicos para alvenaria estrutural e de vedação Métodos de ensaio, NBR 15270-3/2005, Rio de Janeiro, RJ (2005).

[19] INMETRO, Instituto Nacional de Metrologia, Normalização e Qualidade Industrial. Bloco cerâmico - tijolo. Disponível em: http://www.inmetro.gov.br/ consumidor/produtos/tijolo.asp, acesso em 27/11/2008. (Rec.05/09/2008, Rev. 02/02/2009, Ac. 04/04/2009) 